\title{
Mortalidade em potros associada ao parasitismo por Strongyloides westeri ${ }^{1}$
}

\author{
Ricardo B. Lucena², Rafael A. Fighera ${ }^{3}$ e Claudio S.L. Barros ${ }^{3 *}$
}

\begin{abstract}
Lucena R.B., Fighera R.A. \& Barros C.S.L. 2012. [Foal mortality associated with Strongyloides westeri parasitism.] Mortalidade em potros associada ao parasitismo por Strongyloides westeri. Pesquisa Veterinária Brasileira 32(5):401-404. Departamento de Patologia, Universidade Federal de Santa Maria, Camobi, Santa Maria, RS 97105-900, Brazil. E-mail: claudioslbarros@uol.com.br

An outbreak of Strongyloides westeri infection in foals is described. Five out six weanling thoroughbred foals developed diarrhea, loss of weight, hipoalbuminemia and anemia. Large numbers nematode eggs were detected in the feces of two of those foals. Three foals died naturally and a fourth was euthanized in extremis. Necropsy findings from three foals were subcutaneous edema, ascites, hydrothorax and petechiae in the duodenal mucosa. Histologically, changes were restricted to the duodenum and were characterized by villous atrophy and limphoplasmacytic inflammatory infiltrate in the lamina propria. In the villous tips there were multiple small cavities filled by nematode parasites and embryonated eggs. Based on the epidemiology, morphological characteristics of the nematodes and necropsy finds from the necropsy of three affected foals, a diagnosis of $S$. westeri infection was made.
\end{abstract}

INDEX TERMS: Diseases of horses, diseases by parasites, diarrhea, anemia, Strongyloides infection, Strongyloides westeri.

RESUMO.- É descrito um surto da infecção por Strongyloides westeri em potros. Cinco de seis potros recém desmamados desenvolveram diarreia, perda de peso, hipoalbuminemia e anemia. Grande número de ovos de nematódeos foi detectado nas fezes de dois desses potros. Três potros morreram naturalmente e um quarto foi eutanasiado in extremis. Os achados de necropsia em três potros consistiam de edema subcutâneo, ascite, hidrotórax e petéquias na mucosa do duodeno. Histologicamente, as alterações eram restritas à mucosa do duodeno e caracterizadas por atrofia das vilosidades e infiltrado inflamatório linfoplasmocítico na lamina propria. Múltiplas pequenas cavidades preenchidas por parasitas nematódeos e ovos embrionados ocorriam na ponta das vilosidades duodenais. Com base na epidemiologia, nas características morfológicas dos nematódeos e nos achados de necropsia no três potros

\footnotetext{
${ }^{1}$ Recebido em 14 de novembro de 2011.

Aceito para publicação em 6 de janeiro de 2012.

${ }^{2}$ Programa de Pós-Graduação em Medicina Veterinária, área de concentração em Patologia Veterinária, Centro de Ciências Rurais (CCR), Universidade Federal de Santa Maria (UFSM), Camobi, Santa Maria, RS 97105900, Brasil.

${ }^{3}$ Departamento de Patologia, UFSM, Santa Maria, RS. *Pesquisador 1A do CNPq. Autor para correspondência: claudioslbarros@uol.com.br
}

necropsiados, um diagnóstico de infecção por $S$. westeri foi feito.

TERMOS DE INDEXAÇÃO: Doenças de equinos, doenças parasitárias, diarréia, anemia, estrongiloidose, Strongyloides westeri.

\section{INTRODUÇÃO}

Strongyloides spp. são pequenos nematódeos filamentosos da ordem Rhabditida que parasitam o intestino delgado de várias espécies de animais domésticos (Quadro 1). Ruminantes são parasitados por Strongyloides papillosus, cavalos por $S$. westeri, suínos principalmente por $S$ ransomi, cães por $S$. stercoralis e gatos por $S$. felis, $S$. planiceps $(=S$. catti) e $S$. stercoralis no intestino delgado e $S$. tunefaciens no cólon (Brown et al. 2007). Os vermes são fêmeas partenogenéticas que produzem larvas capazes de infecção direta no hospedeiro ou de se desenvolver em gerações de machos e fêmeas de vida livre. A progênie da geração de vida livre adota então uma existência parasitária (Lyons et al. 1991, Lyons et al. 1993, Taylor et al. 2007)

A infecção por $S$. westeri dos potros pelas larvas de vida livre no terceiro estágio ocorre de forma passiva, através da pastagem ou do aleitamento, ou ativa, quando da penetração pela pele íntegra (Lyons et al. 1973). A infecção por $S$. westeri tem sido associada a quadros de diarreia em potros 
Quadro 1. Infecções por Strongyloides spp. em espécies domésticas (Fontes: Brown et al. 2007, Taylor et al. 2007)

\begin{tabular}{|c|c|c|c|}
\hline Espécie afetada & Espécie do nematódeo & Características do nematódeo & Efeitos no hospedeiro \\
\hline Equinos & S. westeri & $\begin{array}{l}\text { Vermes delgados e filiformes; as fêmeas pa- } \\
\text { rasitas têm 6-9 mm de comprimento. }\end{array}$ & $\begin{array}{l}\text { Potros (geralmente abaixo de } 4-5 \text { meses) com } \\
\text { alta infestação mostram diarreia aguda, ocasio- } \\
\text { nalmente fatal, com fraqueza e emaciação. Ani- } \\
\text { mais mais velhos podem abrigar grandes cargas } \\
\text { parasitárias sem mostrar sinais clínicos. }\end{array}$ \\
\hline Ruminantes & S. papillosus & $\begin{array}{l}\text { Vermes delgados e filiformes; as fêmeas pa- } \\
\text { rasitas têm geralmente menos que } 1 \mathrm{~mm} \text { de } \\
\text { comprimento }\end{array}$ & $\begin{array}{l}\text { Os sinais clínicos mais comuns, usualmente ob- } \\
\text { servados nos bezerros mais novos, são diarreia, } \\
\text { anorexia, apatia, perda de peso e redução na taxa } \\
\text { de crescimento. Infecções muito fortes podem } \\
\text { ocasionalmente, causar morte em lactentes ou } \\
\text { animais jovens. Há relatos raros de uma sín- } \\
\text { drome de morte súbita, de patogênese desco- } \\
\text { nhecida, associada à infecção. }\end{array}$ \\
\hline Suínos & S. ransomi & $\begin{array}{l}\text { Vermes delgados e filiformes; as fêmeas pa- } \\
\text { rasitas têm 3-4 mm de comprimento }\end{array}$ & $\begin{array}{l}\text { Em infecções leves não há sinais clínicos. Em in- } \\
\text { fecções pesadas pode ocorrer diarreia com san- } \\
\text { gue, anemia, emaciação e morte súbita. Durante a } \\
\text { fase migratória pode haver tosse, dor abdominal } \\
\text { e vômitos. }\end{array}$ \\
\hline Cães & S. stercoralis & $\begin{array}{l}\text { Vermes delgados e filiformes; as fêmeas pa- } \\
\text { rasitas têm } 2 \mathrm{~mm} \text { de comprimento }\end{array}$ & $\begin{array}{l}\text { Infecções fatais podem ocorrer em filhotes de } \\
2-3 \text { meses de idade. Cãezinhos infectados ema- } \\
\text { grecem e se desidratam por diarreia, por vezes } \\
\text { tingida de sangue. Potencial zoonótico. }\end{array}$ \\
\hline \multirow[t]{4}{*}{ Gatos } & S. felis $(=S$. catti $)$ & $\begin{array}{l}\text { Vermes delgados e filiformes; as fêmeas pa- } \\
\text { rasitas têm } 5 \mathrm{~mm} \text { de comprimento }\end{array}$ & $\begin{array}{l}\text { Pouco patogênico. Pode causar leves focos de } \\
\text { pneumonia intersticial granulomatosa ou eosino- } \\
\text { fílica em resposta à migração de larvas pelo pul- } \\
\text { mão. Diarreia é incomum. }\end{array}$ \\
\hline & S. planiceps & $\begin{array}{l}\text { Vermes delgados e filiformes; as fêmeas pa- } \\
\text { rasitas têm 2,4-3,3 mm de comprimento }\end{array}$ & Não patogênico. \\
\hline & S. stercoralis & $\begin{array}{l}\text { Vermes delgados e filiformes, as fêmeas pa- } \\
\text { rasitas têm } 2 \mathrm{~mm} \text { de comprimento. }\end{array}$ & $\begin{array}{l}\text { Infecção do intestino delgado. Raramente asso- } \\
\text { ciada com diarreia crônica. }\end{array}$ \\
\hline & S. tumifaciens & $\begin{array}{l}\text { Vermes delgados, filiformes, as fêmeas para- } \\
\text { sitas têm } 5 \mathrm{~mm} \text { de comprimento }\end{array}$ & $\begin{array}{l}\text { A infecção ocorre no cólon, onde forma nodu- } \\
\text { lações; raramente associado com diarreia } \\
\text { crônica. }\end{array}$ \\
\hline
\end{tabular}

jovens (Lyons et al. 1991, Netherwood et al. 1996). Embora infecções graves sejam relatadas como causa de morte de potros imunossuprimidos (Hagelskjaer 1994, Brown et al. 1997), são raros os relatos da infecção por $S$. westeri como causa de morte em equinos.

O objetivo é descrever e discutir os achados clínicos e patológicos de um surto de infecção por Strongyloides westeri associado à mortalidade em potros no Rio Grande do Sul.

\section{MATERIAL E MÉTODOS}

Os casos de estrongiloidose foram observados em um haras do município de Itaqui Latitude $29^{\circ} 08^{\prime}$ S (Longitude $56^{\circ} 33^{\prime} 0$ ) no Rio Grande do Sul. 0 sangue foi colhido de três potros para realização de hemograma e determinação da albumina sérica. 0 método de flutuação para contagem do número de ovos por grama de fezes (OPG) foi realizado em dois potros. Três potros foram necropsiados e amostras colhidas de tecidos do intestino delgado, respiratório, nervoso, endócrino, reprodutor tegumentar, foram fixadas em formalina, processadas para histologia e corados com haematoxilina-eosina (HE).

\section{RESULTADOS}

Em fevereiro de 2010, um total de seis potros PSI (cinco machos e uma fêmea), foram desmamados aos quatro meses de idade, dosados com ivermectina e levados para potreiro de um hectare com pastagem rala. Após 15 dias do desmame, cinco potros mostraram diarreia e emagre- cimento. Todos os potros foram novamente dosados com ivermectina, e receberam fluidos IV contendo $5 \%$ de dextrose $(350 \mathrm{ml} / \mathrm{h})$, e antibioticoterapia (trimetoprima-sulfametoxazol e penicilina). Os potros não responderam ao tratamento e a diarreia persistiu por aproximadamente um mês. As mucosas de todos os potros estavam pálidas. Havia edema dos membros pélvicos em dois potros. Dois potros morreram antes que fossem feitos exames complementares. Exames hematológicos de três potros (potros 3, 4 e 5) revelaram anemia (PVC 16,10\%; 18,2\% e 25\%) e hipoalbuminemia $(1,79 \mathrm{~g} / \mathrm{dl}, 1,92 \mathrm{~g} / \mathrm{dl}$ e $2,2 \mathrm{~g} / \mathrm{dl})$. 0 método de flutuação foi realizado para contagem do número de ovos por grama de fezes (OPG) realizada em dois potros revelou marcado e moderado parasitismo (150 e 1.600). Em quatro dos cinco potros, o quadro evoluiu para decúbito lateral. Três potros morreram e um foi eutanasiado in extremis. 0 quinto potro foi dosado com tiabendazol e a diarreia cessou.

Os achados de necropsia em três potros consistiam de edema subcutâneo, ascite, hidrotórax e petéquias na mucosa do duodeno. Histologicamente, as lesões se restringiam ao duodeno caracterizavam-se por atrofia das vilosidades e infiltrado inflamatório linfoplasmocítico na lâmina própria. No topo das vilosidades havia múltiplas cavitações preenchidas por parasitas nematoides e ovos parasitários embrionados (Fig.1). Os nematódeos tinham 10-25 $\mu \mathrm{m}$ de diâmetro, eram constituídos por musculatura platimiariana, pseudoceloma, um longo esôfago rabdi- 


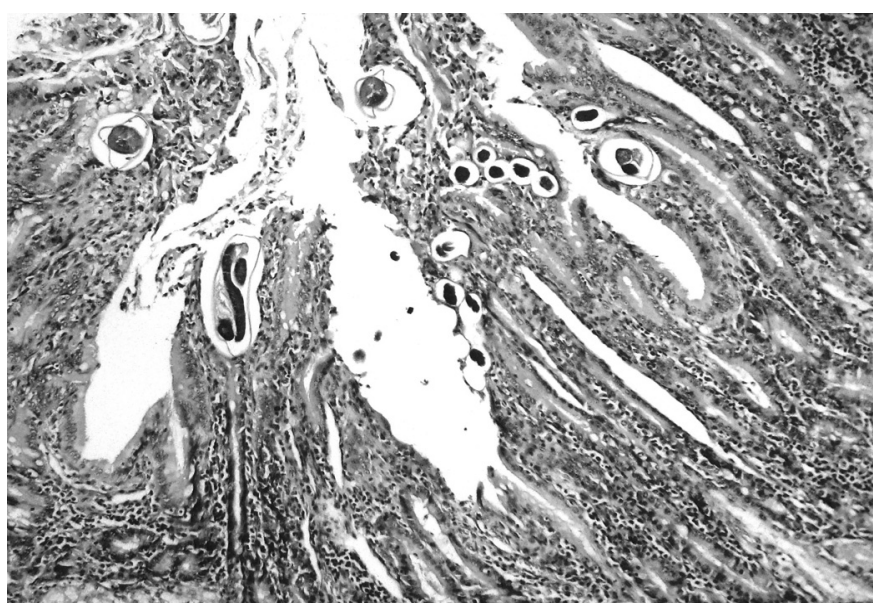

Fig.1. Duodeno de potro infestado por Strongyloides westeri. Enterite linfoplasmocitária difusa acentuada, com atrofia das vilosidades, associada a numerosos parasitas e ovos embrionados livres dentro de túneis localizados principalmente na superfície epitelial. Os parasitas adultos são observados em cortes transversais e longitudinais, contendo ovos embrionados. HE, obj.20x.

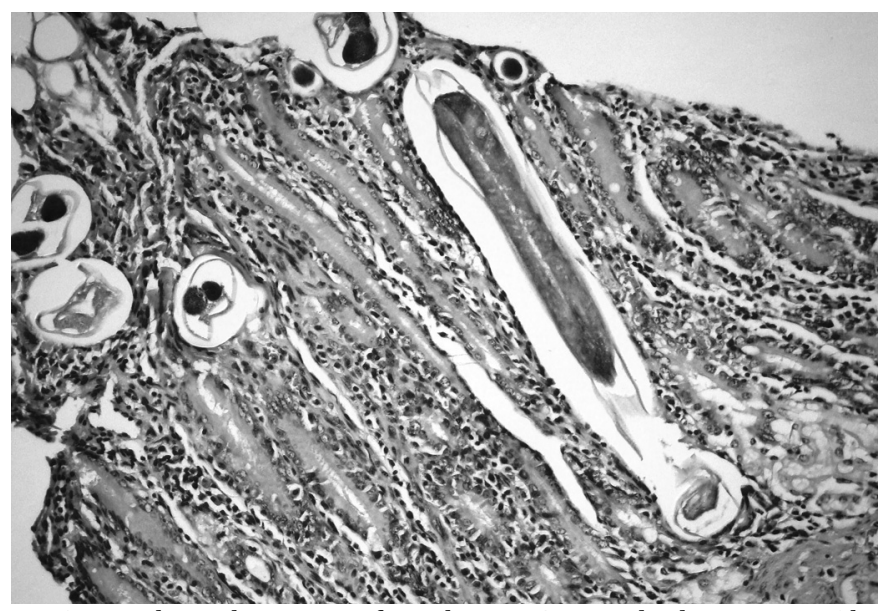

Fig.2. Duodeno de potro infestado por Strongyloides westeri. Observa-se um corte longitudinal de parasita adulto, constituído por cutícula lisa, musculatura platimiariana, pseudoceloma e um longo esôfago rabditiforme. Ao lado existem outros parasitas em cortes transversais e ovos livres em túneis HE, obj.40x.

tiforme (Fig2) com bulbo terminal e trato digestivo tubular delineado por epitélio cuboide baixo. No trato genital do parasita havia de um a dois ovos grandes, basofílicos e uninucleados; ovos eram observados, também, livres em cavitações na mucosa superficial. Foi feito um diagnóstico de infecção por Strongyloides westeri.

\section{DISCUSSÃO}

Um diagnóstico de helmintose deve ser reservado para casos onde, idealmente, três critérios sejam preenchidos: (1) o helminto está presente em números compatíveis com a doença; (2) as lesões tipicamente causadas pelo agente estão presentes e (3) há um conjunto de sinais compatíveis com os mecanismos patogênicos sabidamente associados com o verme (Brown et al. 2007). No presente surto, o diagnóstico de estrongiloidose foi feito baseado na epidemiologia, nos sinais clínicos, patologia característica e observação de ovos e parasitas adultos com morfologia compatível com Strongyloides westeri (Taylor et al. 2007)

Um conjunto de fatores contribuiu para a ocorrência deste surto. Primeiro, os potros foram desmamados muito jovens, aos quatro meses de idade, devido o mal estado corporal das éguas. Em seguida foram levados para um campo com alta lotação, além de a pastagem estar pobre. Adicionalmente potros de diferentes idades haviam pastado no potreiro com suas mães uma semana atrás. 0 ciclo de vida de Stongiliodes westeri inicia quando ovos embrionados viáveis são eliminados nas fezes de potros. No meio ambiente, a larva de primeiro estágio $\left(L_{1}\right)$ eclode dos ovos e passa a larva de segundo estágio $\left(L_{2}\right)$. Em ambos os estágios as larvas se alimentam de matéria orgânica até que passem ao terceiro estágio $\left(\mathrm{L}_{3}\right)$ infectante. O desenvolvimento desde o estágio de ovo até o estágio infectivo $\mathrm{L}_{3}$ requer apenas alguns dias se as condições são favoráveis (Lyons et al. 1991). 0 surto deste relato ocorreu no verão, quando há maior precipitação pluviométrica e temperaturas mais levadas, condições favoráveis para a ocorrência de grande número de larvas infectantes na pastagem. Adicionalmente, larvas de $S$. westeri podem apresentar uma forma de desenvolvimento indireto nas pastagens por uma variação do ciclo de vida. Em vez de se tornar infectantes, as larvas $\mathrm{L}_{2}$ se desenvolvem em larvas $L_{3}$ rabditoides. Essas larvas então se desenvolvem em larvas $\mathrm{L}_{4} \mathrm{e}$, em seguida, em adultos machos e fêmeas de vida livre, que produzem ovos que eclodem as larvas $L_{1}$, estas por sua vez se desenvolvem em larvas $L_{2}$ e, eventualmente, tornam-se larvas infectantes $\mathrm{L}_{3}$. Este ciclo de vida alternativo aumenta consideravelmente o número de larvas infectantes provenientes de um único ovo (Lyons et al. 1991).

Diagnósticos de infecção por $S$. westeri são baseados na observação de ovos embrionados nas fezes frescas de potros por métodos de flutuação. Esses ovos são distinguidos dos grandes ovos de Strongylus, não embrianados (Lyons et al. 1991). A avaliação do OPG realizada em três potros, constatou a presença de ovos embrionados compatíveis com $S$. westeri em todos, variando de moderada a grande quantidade. No entanto, não há correlação entre o número de ovos por grama de fezes e a dirreia, isto é, um determinado potro pode ter um alto OPG e não demonstrar diarreia, ou por outro lado ter baixo OPG com diarreia. Há ainda relato de potro com infecção sistemica por $S$. westeri com método de flutuação fecal negativa para ovos do parasita; naquele caso específco os autores consideraram que a infecção ainda não estava patente (Brown 1997).

O controle da infecção por Strongyloides westeri pode ser feito pela redução no número de larvas livres e pela remoção das fezes do ambiente fornecimento tanto de locais para manutenção dos animais e camas secos. Em haras os potros devem receber tratamento com anti-helmíntico contra S. westeri com 1-2 semanas de idade (Taylor et al. 2007). Ivermectina parece ser o tratamento de escolha para todas as espécies de Strongyloides (Bowman 2007. 
Agradecimentos.- Parte deste estudo foi desenvolvido e custeado pelo Programa de Cooperação Acadênica Novas Fronteiras (PROCAD-NF) da CAPES. Os custos da presente publicação foram custeados pelo mesmo programa.

\section{REFERÊNCIAS}

Bowman D.D. 2007. Georgi's Parasitology for Veterinarians, $9^{\text {th }}$ ed. Saunders Elsevier, Philadelphia, p.192-195.

Brown C.A., MacKay R.J., Chandra S., Davenport D. \& Lyons E.T. 1997. Overwhelming strongyloisosis in a foal. J. Am. Vet. Med. Assoc. 211:333-334.

Brown C.C., Baker D.C. \& Barker I. 2007. Gastroeintestinal helminthosis, p.232-260. In: Maxie M.G. (Ed.), Jubb, Kennedy, and Palmer's Pathology of Domestic Animals. Vol.2. $5^{\text {th }}$ ed. Saunders Elsevier, Philadelphia.

Hagelskjaer L.H. 1994. A fatal case of systemic strongyloidiasis and review of the literarture. Eur. J. Clin. Microbiol. Infect. Dis. 13:1069-1073.
Lyons E.T., Drudge J.H., Tolliver S.C. \& Granstrom D.E. 1991. The role of intestinal nematodes in foal diarrhoea. Vet. Med. 86:320-328.

Lyons E.T., Drudge J.H. \& Tolliver S.C. 1973. On the life cycle of Strongyloides westeri in the equine. Vet. Parasitol. 59:780-787.

Lyons E.T., Tolliver S.C., Drudge J.H., Granstrom D.E., Sandra S. \& Collins S.S. 1993. Natural infections of Strongyloides westeri: prevalence in horse foals on several farms in central Kentucky in 1992. Vet. Parasitol. 50:101-107.

Netherwood T., Wood J.L.N., Townsend H.G.G., Mumford J.A. \& Chanter N. 1996. Foal diarrhoea between 1991 and 1994 in the United Kingdom associated with Clostridium perfringens, rotavirus, Strongyloides westeri and Cryptosporidium spp. Epidemiol. Infect. 117:375-383.

Taylor M.A., Coop R.L. \& Wall R.L. 2007. Veterinary Parasitology. $3^{\text {rd }}$ ed. Blackwell Publishing, Oxford, p.266-267. 